\title{
Planejamento, gestão e avaliação em saúde: identificando problemas
}

\author{
Health planning, management and evaluation: \\ identifying problems
}

Lilia Blima Schraiber 1

Marina Peduzzi 2

Arnaldo Sala 1

Maria Ines B. Nemes 1

Elen Rose L. Castanhera ${ }^{1}$

Rubens Kon 1

1 Departamento de Medicina Preventiva, Centro de Saúde Escola Samuel B. Pessoa, Faculdade de Medicina da USP,

Av. Dr. Arnaldo 455 $2^{\circ}$ andar, 01246-903, São Paulo, SP, Brasil liliabli@usp.br

2 Departamento de Orientação Profissional e Centro de Saúde Escola Samuel B. Pessoa, Escola de Enfermagem da USP
Abstract This paper presents some relevant issues for the health services from the planning and management perspective while dealing with those work processes which produce health care and assistance. It contributes therefore with the study of the interfaces between management, planning and the labour process in health. Management is considered as a labour process itself, organising and executing health care submitted to a previous productive rationality. On the other hand, some majors problems of the health care and assistance are considered as potential issues to be included in management: the integration of health practices, dealing with the interdisciplinary nature of techniques and the multiprofissional health team, and the health care quality, from a technical scientific efficacy and communicative perspective. Labour is thus conceived as both productive action and interaction. That means considering the connections between the different professional works producing health care and assistance as well as considering those subjective interactions producing shared decisions and communication

Key words Management and Work in Health; Work and Interaction in Health; Planning in Health; Labour Process
Resumo Este texto apresenta um conjunto de problemáticas para o planejamento e a gestão dos serviços de saúde, a partir dos processos de trabalho produtores diretos da assistência e dos cuidados em saúde. Busca, pois, contribuir com questões relevantes ao estudo das interfaces entre a gestão e o trabalho em saúde. Aborda o próprio planejamento e a gestão como produção de um trabalho: o de organização e realização de outros trabalhos, com vistas à racionalidade produtiva dos serviços em seus diversos fins. De outro lado, pontua questões desses outros trabalhos enquanto problemas que podem vir a ser tomados pelo trabalho gestor: a integralidade das ações com interdisciplinaridade das técnicas $e$ interação entre multi-profissionais no trabatho em equipe, ou a garantia de qualidade resolutiva da assistência, tanto como eficácia técnico-científica quanto como adesão e intercomunicação na relação direta entre os diversos profissionais e destes com os usuários dos serviços. Para tanto concebe-se trabalho como processo produtivo e como interação, levando-se em conta as articulações entre as ações em saúde, pelo que representam de ações estratégicas para a produção de cuidados e assistência, bem como as relações intersubjetivas, pelo que representam de ações comunicativas e partilhas de decisões.

Palavras-chave Gestão e Trabalho em Saúde; Trabalho e Interação em Saúde; Planejamento em Saúde; Processo de Trabalho 


\section{Introdução}

Este texto busca trazer à discussão questões relacionadas ao planejamento e gestão, como uma das áreas da saúde coletiva brasileira. As questões apontadas são alguns dos problemas enfrentados no cotidiano dos serviços. Significam para os gestores desafios práticos e possíveis dilemas técnicos, éticos ou políticos, em seus enfrentamentos. Em razão disto, entendemos que serão também problemáticas para o conhecimento, constituindo objetos de investigação, a fim de se explicar suas origens e constituições, como forma de apoiar as resoluções concretas e particulares que o cotidiano dos serviços demanda.

Esta área "planejamento e gestão" pode ser vista como um conjunto bastante amplo de produções técnico-científicas que, de modo mais tradicional, pertenceu a uma das divisões da saúde coletiva já denominada "Planejamento e Administração em Saúde”. Ao longo dos últimos 30 anos que consolidaram no Brasil a saúde coletiva como campo de produção de saber e prática ${ }^{1}$ o planejamento e administração em saúde serviu de eixo aglutinador para objetos de investigação e propostas de intervenção social tão diversas quanto, por exemplo, a gerência de unidades ambulatoriais ou hospitalares, os recursos humanos, os programas assistenciais, a avaliação das atividades e ações dos serviços, financiamento das ações, orçamentos dos setores de produção e dos serviços, entre outros. Tais recortes também resultaram em tão variadas aproximações da realidade dos serviços e das ações em saúde, que para compreender essa área de estudos e intervenção e seu desenvolvimento, a rigor, seria necessário uma pesquisa histórico-epistemológica específica ${ }^{2}$. Um estudo dessa natureza permitiria redispor, da perspectiva classificatória, a produção que hoje encontramos, distinguindo a que pende mais ao polo teórico-conceitual daquela que se apresenta com a qualidade de projeto de intervenção, ou a que delimita objetos referidos ao planejamento daquela que pende mais à administração, identificando com precisão os conceitos e os referenciais teóricos utilizados em cada qual. Isto, sem falarmos da óbvia busca contemporânea de superar esses limites clássicos sob as temáticas da gestão e da avaliação, apontando-se, inclusive, para a superação da dicotomia, também clássica, entre a pesquisa e a intervenção ${ }^{3}$.
Não contando, porém, com tal produção, neste texto, para identificarmos alguns problemas e problemáticas que consideramos importantes, vamos recorrer a uma compreensão de sua história cunhada pela nossa própria experiência de participantes: na qualidade de sujeitos também construtores das mudanças e desenvolvimento do planejamento e administração em saúde. Com isso certamente incorreremos no viés do espaço-tempo em que se deu nossa própria prática, de pesquisadores na área e de profissionais do planejamento e gestão. Por isso o que oferecemos à discussão deve ser necessariamente enriquecido com os demais pontos-de-vista, particulares a outros tantos personagens partícipes da saúde coletiva e que constituem nossa comunidade de interlocução científica e profissional.

Adiante-se que nosso viés deriva do fato de que vivemos a situação de gerentes, via de regra, de nível local, isto é, de unidade específica de prestação de serviços com produção assistencial direta, também conhecida como a "ponta do sistema de saúde": uma unidade básica do tipo Centro de Saúde. Com isto privilegiamos tanto este nível da entrada em um sistema, quanto as interfaces entre o planejamento/gestão e o processo de trabalho em saúde, em que as questões fundamentais são questões assistenciais bem próprias, como as da promoção da saúde e prevenção primária, relativamente a outros níveis de prevenção, e tratamentos de recuperação clínica básica, relativamente a outros níveis de intervenção médica. São elas:

- integralidade das ações, para a intervenção médico-sanitária articulada e conformando modelo de assistência de natureza técnica interdisciplinar específica;

- interação entre multiprofissionais no trabalho em equipe;

- qualidade resolutiva da assistência muito mais da perspectiva da produção direta das ações do que do modelo de assistência genérico, gerando outras questões como: eficácia técnico-científica na resolução de casos, adesão e intercomunicação na relação direta de sujeitos (profissionais-usuários, profissionaisprofissionais e profissionais-gerentes) e delimitação do alcance e limites dos cuidados;

- revalorização desse nível de atuação profissional, em geral, desqualificado como exercício da profissão em saúde, particularmente no caso de médicos, em primeiro lugar, e enfermeiros, em segundo lugar. 
Esta última questão merece uma observação, pois, se as demais serão também problemas e problemáticas dos outros níveis de um sistema de saúde, mesmo que cabendo a cada qual repensá-las, neste nível da unidade básica e sua atenção (primária), há a necessidade de definir e requalificar a assistência e o trabalho: o que é e quanto vale essa atenção primária e a correlata tecnologia básica de intervenção, em que a ação assistencial e ações de outro tipo como a educativa ou da assistência social, confundem-se com muita freqüência, tanto no bom sentido da interação de profissionais e articulação das ações, quanto no sentido de desqualificar, por exemplo, a educação, facilmente reduzida a uma intervenção biomédica, ou desqualificar a esta por ser "muito educativa" ou muito "assistência social" e menos biomédica, permitindo a confusão ideologicamente interessada aos modelos hegemônicos, da atenção primária como medicina da pobreza e da tecnologia apropriada como intervenção sem saber ou sem ciência ${ }^{4}$.

Este é, portanto, um recorte bem particular sobre as questões e que é próximo a alguns modelos assistenciais (Paim, 1993) ou programas particulares (Mendes, 1996), como por exemplo Saúde da Família, pela preocupação com esta assistência locada imediatamente no âmbito da vida privada (família) ou do cotidiano social (vida comunitária). Não recobre todas as situações nem do trabalho direto, nem da gestão em saúde. Não obstante, acreditamos que suas problemáticas possam contribuir para as demais situações de modo analógico, isto é, pela similitude de questões que terão que tratar os gestores locais de administração pública, mesmo quando em nível mais amplo tal como os distritos sanitários, por exemplo. Isto porque gestores de vários níveis sempre se envolvem com a implementação de uma dada política assistencial, implantando uma certa organização da produção dos serviços em acordo com as diretrizes do SUS e, ao mesmo tempo, buscando, em especial, a integralidade das ações e as interações que produzem cuidados diretos à população.

Esta última pretensão - a integralidade das ações e as interações entre indivíduos e atores resultantes - constituiu, afinal, nossa eleição também de pesquisa, investigando as possibilidades e os limites da integração entre a assistência clínica e aquela dos programas de prevenção e promoção da saúde na assistência da unidade básica, o que se denominou "ação programática em saúde" (Schraiber, 1990; Schraiber et al.,1996). Examinada da perspectiva de produção direta dos cuidados - sua organização e seu dia-a-dia no cotidiano do trabalho em saúde, mais do que pelo ângulo dos modelos de consumo ou de políticas de Estado - tal modo de trabalhar e assistir propiciou o estudo da integração entre práticas realizadoras de trabalho em saúde: possibilidades e limites da interação entre os profissionais da prática clínica, e seu agir assentado na aproximação individual dos problemas de saúde, e aquele da prática sanitária, de aproximação populacional ou seus segmentos, sendo esta interação propiciadora de questões tanto da interdisciplinaridade dos saberes especializados, quanto da interatividade na relação entre os usuários e o próprio serviço. Experiência essa que, como pesquisadores, avaliamos, e da qual procuramos extrair o conhecimento técnico-científico que pudesse contribuir para o planejamento e gestão de serviços de saúde.

Mas não é nosso intuito novamente trabalhar a proposta da ação programática, seja como organização, seja como prestação de serviços. Pretendemos, sim, levantar algumas questões que essa experiência nos colocou. Estamos certos de que serão compartilhadas com gestores que também viveram ou vivem, na referida implementação das políticas de saúde, o empreendimento de buscar no planejamento e avaliação, e por meio dos modelos assistenciais que propõem, a máxima qualidade assistencial de seus serviços (o que certamente inclui, além da competência técnico-científica, a viabilidade econômico-financeira da produção), bem como a realização das diretrizes políticas de nossa reforma sanitária.

As questões que trazemos serão abordadas, como já dito, pelas interfaces entre gestão e processos de trabalho em saúde. Estes últimos compreendem o trabalho diretamente produtor dos cuidados e das ações assistenciais. Trata-se, portanto, em nosso caso, das questões desse trabalho direto e de seu trabalhador: o médico, o enfermeiro, o psicólogo, o assistente social, o auxiliar de enfermagem, etc. Vamos destacar questões que a partir desse processo de trabalho assistencial se colocariam para o trabalho do gestor. São especificidades e problemas para o momento da prestação direta dos serviços, e alguns podem não se configurar, ainda, como problemas também para o planejamento e a gestão. Vale dizer que o ges- 
tor acatará ou não tais questões como sua problemática própria. Acreditamos que o gestor assim o fará sempre que aquelas questões se apresentarem como algo a disciplinar ou a transformar, do ponto de vista da organização e funcionamento geral do conjunto dos trabalhos produtores diretos das ações assistenciais.

Tal como parte da bibliografia aponta, essa última perspectiva implica propor projetos de intervenção na organização do coletivo de trabalho. Não o faremos exatamente desse modo e, então, não estaremos, por ora, propondo formas de gestão. Mas estaremos levantando um conjunto de questões que, da nossa experiência, deveriam ser tomadas como problemas para o planejamento e a gestão em saúde.

Antes, porém, registremos que, em termos genéricos, a assistência fornecida à população, enquanto um conjunto coordenado de ações e os produtos esperados em seu todo, tem sido objeto da organização dos serviços, situação em que os gerentes de unidades (já não somente básicas ou de atenção primária) estão diante da necessidade de articular os trabalhos produtores de cuidados e os princípios técnicos (do conhecimento científico), organizativos (do Sistema de Saúde) e ético-políticos (da Política Social em Saúde) da "boa prática” em saúde. Entenda-se esta "boa prática” como sendo aquela que, cientificamente, é a esperada. E que será operada segundo um modo de prestar os serviços que cumpra tanto com as expectativas de consumo das sociedades estruturadas na forma mercado, quanto com as expectativas políticas e éticas da máxima distribuição deste benefício que constitui a assistência à saúde e das conquistas do direito à saúde com base na reforma sanitária brasileira. Por isso, dentre as questões de interesse para a gestão em saúde, principalmente para enfrentar os problemas dessa "ponta do sistema" que representa a assistência direta e a produção dos cuidados, estarão as contempladas pelas interfaces que elegemos: da ação técnica ou da tecnologia dos cuidados com o planejamento e a gestão dos serviços.

Não obstante, algumas questões que estaremos colocando são fruto de recentes estudos sobre o trabalho produtor direto dos cuidados, ampliando o leque das interfaces a serem consideradas pela gerência, o que julgamos nossa particular contribuição, neste momento. Isto posto, cabe-nos iniciar especificando como vemos, hoje, o próprio trabalho dessa gerência e algumas de suas questões tecnológicas.

\section{Planejamento e gestão: desafios atuais}

Em uma preliminar colocação, bem genérica, diremos que as considerações que seguem são fruto do movimento histórico do próprio campo da saúde coletiva, tal como realizado na área particular do planejamento e administração em saúde, em função da especificidade dessa área.

Consideremos a mudança do tradicional papel do administrador público, ao somar à função anterior, aquela de gerente de serviços de saúde. Vale dizer, a de organizar e controlar unidades produtoras de cuidados de assistência médica em redes do setor público, tal qual nos mostra o estudo de Castanheira (1996). Isto foi produto das políticas de saúde brasileiras na construção do próprio SUS e do modo peculiar como a saúde foi sendo tomada como questão social e questão de Estado. O Estado brasileiro interferiu no mercado e nos postos de trabalho na saúde, praticando políticas de proteção social tais que abriu espaços profissionais em seus dispositivos e aparelhos prestadores de serviços, configurando-se não apenas como Estado regulador mas Estado provedor. Assim, à clássica exigência da figura de "representante do interesse público", tal como emergiu nos anos 30-40 o agente do Estado e suas políticas, caracterizando o administrador público, somou-se a figura do profissional que, técnico em organizar a produção - o gerente, deve otimizar a produtividade, manejar os problemas e os conflitos cotidianos, para a produção de serviços assistenciais oferecidos ao consumo individual e de mercado, envolvendo todas as questões da eficácia/eficiência empresarial, ainda que empreendimento ("empresa”) estatal.

Do administrador em saúde pública ao gerente da rede de unidades e serviços do setor público de produção de assistência médica em articulação com o setor privado, este personagem contemporâneo - o gestor público, defronta-se com uma prática de grande complexidade, resultante dos novos desafios deste novo lugar. E isto será, de um lado, garantir a universalidade e a eqüidade na prestação de serviços; possibilitar a participação popular e profissional nos processos decisórios correlatos à organização da produção e também na execu- 
ção dos cuidados em saúde; lidar com a integralidade das ações, criando espaços e formas de interação no trabalho cotidiano e gerenciando conflitos, tal como convém ao representante dessa esfera pública que se plasmou nas leis e normas da reforma. Mas será, de outro lado, encontrar a melhor via de obter alta resolutividade e boa qualidade técnico-científica das ações que serão produzidas. Estas últimas exigências são produto e produtoras, também, da competência de incorporar todo o conhecimento científico já produzido e operado, hoje, nas diversas tecnologias de intervenção em medicina e em saúde pública, porém, com crítico discernimento - de técnico e de gerente - tal como necessário (e como convém) para fazer frente à sua específica qualificação profissional. Esta, além de compreender as decisões quanto à intervenção apropriada nos processos saúde-doença nas duas esferas que agora se entrecruzam (individual e populacional), deve contemplar a administração da oferta e consumo dos serviços, no formato demanda individualizada por cuidados e outros serviços e que, ainda mais, se dispõe como consumo de bens em mercado 5 .

Não há dúvida de que esta transformação do planejamento e administração em saúde muda e renova as problemáticas e as técnicas de organização/gestão/avaliação às quais esse personagem precisa, doravante, recorrer.

Em segundo lugar, considerando-se a especificidade dessa área do planejamento e administração em saúde, registre-se que no campo da saúde coletiva ela representa o locus da produção técnico-científico de caráter mais aplicado, vale dizer, a porção da saúde coletiva que traduzirá suas ciências e suas tecnologias-base, como por exemplo a epidemiologia, ou a biomedicina ou a sociologia ou a antropologia ou a matemática e estatística, em conhecimentos que são imediatamente propostas de intervenção nos serviços: tecnologias de organização e funcionamento de espaços produtores da intervenção em medicina ou em saúde pública, prestando serviços e cuidados médicos e sanitários. Isto representa, quando tais intervenções também alcançam os processos produtores diretos dos cuidados e a integração neste nível clínico de atuação, como por exemplo a "ação programática em saúde", interferências desde a estruturação dos serviços nas tecnologias e técnicas clínicas e sanitárias, mudando os modos mais tradicionais do agir profissional.
Isto tudo também quer dizer que, dificilmente, essa produção técnico-científica do planejamento e gestão se caracterizará por teoria mais abstrata, bem como, dificilmente, pode deixar de tratar dos conflitos políticos e éticos, perpassando os conflitos técnicos: entre a gerência e os profissionais do cuidado direto; ou desses últimos entre si; ou, mesmo, entre o serviço e seus usuários.

Dentro dessa especificidade e em razão dessa história, é que veremos a área interessar-se por problemas que vão se deslocando do plano macro social, tal como se caracterizou em sua constituição inicial, quando a planificação surgiu como instrumento de atuação/renovação do Estado, para a microfísica das ações assistenciais (Kon, 1997). Se o plano macro social pode ser representado pelo Estado e suas questões de planejamento/administração - em que há que se ocupar com a correta enunciação da boa norma geral de proteger/produzir saúde, no âmbito do qual o consumo da assistência é um dos itens, o micro social é o deste consumo, plano da prestação direta de serviços assistenciais. Este é representado pelas instituições e estabelecimentos produtores de serviços, em que há que se ocupar com a boa realização prática das normas, com o que se requer do planejamento uma habilidade de tecnologia do político: o domínio da arte de flexibilizar as normas para o cotidiano particular deste ou daquele estabelecimento ou conjunto deles, e não mais com o geral social, ainda que sigam sendo tais atuações, com bastante freqüência, questões da esfera organizativa da oferta dos serviços para consumo.

Neste movimento de redelimitações das situações que passam a ser alvos de propostas e estudos da área, redefinindo, pois, objetos preferenciais das pesquisas e das intervenções, podemos observar um outro, de natureza metodológica: a área cada vez mais se desvia da aproximação estrutural da organização e da administração, rumando em direção às dinâmicas interativas dos indivíduos, com o que vem produzir abordagens mais processuais das organizações, dando visibilidade à gerência como o lugar do desempenho em redes interativas - interação do gestor com outras relações interativas, em uma ação sobre a ação de outros (de profissionais e de usuários), ressaltando os problemas dos sujeitos e seus valores, das culturas e seus comportamentos práticos, como parte das flexibilizações das nor- 
mas. O que produziu a interatividade e a comunicação como também problemáticas do planejamento e das técnicas de gestão, somando-se às questões da organização.

Todo esse movimento dos problemas a serem enfrentados geraram, como parte do desenvolvimento da área original do planejamento e administração em saúde, um correlato movimento de individualização, e também de incorporação, de noções e conceitos no ideário do planejamento e da administração em saúde. Idéias que tem sido operadas como fundamentos para o conhecimento e para a ação social. Por exemplo, às noções-base 'planejamento', 'administração', vão se somando as de gerência, gestão, organização tecnológica, modelo assistencial e avaliação em saúde. Isto sem falar daquelas que são tributárias de sínteses com outras áreas da saúde coletiva, tal qual a epidemiologia ou as outras ciências humanas que não a economia, base para o planejamento e a administração. Nesta última categoria comparecem, entre tantas, as noções de vigilância, processo de trabalho em saúde, agir comunicativo, atores e agentes em saúde, autonomia, empoderamento e emancipação de profissionais ou usuários, representações profissionais ou populares, etc.

No entanto, percebemos que essas noções cunhadas, desmembradas de suas raízes originais, vêm sendo progressivamente utilizadas como substitutas das anteriores, novas idéias-base para intervenções ou estudos em que vão sendo operadas com a qualidade de conceitos independentes. Com isso, um grande leque de questões passa a se apresentar para a área do planejamento e administração em saúde como parte de sua substância mesma, sem que, necessariamente, possamos perceber tal pertencimento, em termos do sentido histórico e mesmo epistemológico das modificações que ocasionam.

Contudo, como dissemos, recuperar essas raízes com certa exatidão e traçar a historicidade desses novos conceitos, é uma tarefa a se fazer. O que doravante apresentaremos são apenas algumas das questões que, dialogando com os processos de trabalho no interior da produção de serviços, estão colocadas para o gestor em saúde e que, na qualidade de possíveis objetos de pesquisas e recortes de intervenção, se revelam incitantes poderosos a instigarem nossa atenção.

\section{Ciência, trabalho e processo de trabalho em saúde}

De modo sintético enumeremos algumas especificidades da ação que chamamos trabalho, para colocarmos como questão a dimensão teleológica dessa ação, vale dizer, o trabalho como ação instrumental. Instrumental, pelo ângulo da consecução de produtos esperados, com base em regras técnicas delimitadas. Do ponto de vista normativo e das relações sociais, a instrumentalidade pode adquirir um caráter estratégico ou comunicativo, conforme seja a ação mais autonomizada e independente das interações ou seja produto pactuado nas relações intersubjetivas. Essas últimas considerações fundam-se na distinção habermasiama da ação estratégica e ação comunicativa (Habermas, 1989; 1994). Essa abordagem tem sido estudada no campo do planejamento e dela também iremos nos valer, aqui, para retomar a dupla especificidade do trabalho como ação social: o trabalho como ação produtiva, dentro da racionalidade dirigida a fins dados, isto é, a teleologia que lhe é própria, e como ação comunicativa, o trabalho como interação social. Essas especificidades consubstanciais à ação do trabalho, são, conforme Habermas, analiticamente distinguíveis mas mutuamente irredutíveis, abrindo a possibilidade de investigarmos dentro do agir estratégico do trabalho o modo concreto de realização da interação social, questão a que voltaremos adiante. Por ora, examinemos características do trabalho como ação estratégica.

A primeira está no fato de que sua ação não é qualquer, mas intencionalmente realizada. Intenção que se pauta pela finalidade dessa ação, sempre socialmente reconhecida e reiterada em sua legitimidade. O que ocorre porque, em segundo lugar, é uma ação que produz algo para a sociedade, satisfazendo as necessidades de seus indivíduos, tal como um bem ou um serviço. Por isso, em terceiro lugar, tem que alcançar os resultados esperados e apresenta sempre um produto a seu final. É ação cujos resultados são igualmente reconhecidos/autorizados na sociedade. Em quarto, vamos lembrar que, para tanto, essa ação deve ajustar meios a seus fins, o que lhe confere uma determinada racionalidade de operação. Cria, em quinto lugar, um conhecimento tanto acerca dos referidos meios, diante do objeto de sua intervenção e de sua finalidade, quanto um conhecimento acerca da operação a ser feita, is- 
to é, qual o modo de produzir adequado para o produto pretendido, modo esse que passa a estar contido em uma técnica, isto é, um saber-fazer. Esta técnica poderá, mediante o ensino, ser transmitida de um a outro agente do trabalho, sem que se perca essa qualidade de operação corretamente exercida, componente importante da técnica.

Vamos tentar melhorar essa noção de técnica ${ }^{6}$. Extraída da idéia grega de arte - "disposição pela qual fazemos coisas com a ajuda de um regra verdadeira” (Ross, 1987: 222), a técnica é manipulação, intervenção manual que produz coisas, resulta em produtos, obras exteriores ao fazer, com o concurso de conhecimentos. É, assim, exercício de saber, ação artificial mediante o que há intervenção especificamente realizada para a obtenção do produto.

Por isso trabalhos são atos técnicos; os processos de trabalho valem-se de técnicas embora a técnica não recubra todas as questões envolvidas no trabalho, assim como o trabalho não recobre todas as atividades que são técnicas. No ensino das técnicas adestra-se o agente do trabalho. Mas a transposição não é tão imediata. Basta lembrar que no caso das técnicas de base científica, quando o saber-fazer tem por fundamento a ciência, ensina-se, muitas vezes, mais sistematicamente os conhecimentos científicos que nos informam acerca do objeto sobre o qual vamos intervir, do que sobre a ação da intervenção, principalmente no contexto da produção dos serviços ou do cotidiano do trabalho, o que corresponderia não à técnica em abstrato, como teoria, senão o saber diretamente aplicado, saber operante do trabalho.

Mas destaquemos o fato de que o mencionado conjunto de especificações dos atos técnicos confere ao trabalho a possibilidade de ser ação repetida, e por muitas mãos diferentes, com alguma garantia de mesmo resultado. Isto é, um coletivo de agentes (os profissionais da técnica), que são pessoas diferentes e com talentos igualmente diversos, ou com sentimentos, desejos e opiniões também diversos, e mesmo distintas formas de apreender o saber exigido pela ação, esse conjunto de profissionais age com regularidade do mesmo modo e produz, até nem sempre com meios exatamente iguais em razão dos contextos do trabalho, produtos bastante próximos, que satisfazem pessoas também diferentes, e satisfazem de forma bem parecida.
Essa repetitividade, a capacidade de se reiterar e agir como intervenção que pode ser, de fato, antevista e conformar o projeto da ação, dá-se pelo caráter mais rotineiro de seu "modo de fazer", ao que poderíamos chamar de "tecnicalidade" do trabalho. Isto quer dizer que, de certa forma, há uma possibilidade do saber de operação reter, enquanto saber, previamente à ação em curso, o virtual da ação. Destaca-se assim a presença desse saber, anterior, mas não externo, ao fazer. Esta presença será tão mais forte quanto mais as técnicas forem complexas, tal como as que envolvem conhecimento científico. Por isso o aparecimento das técnicas complexas com a moderna tecnologia instrumental permitiu que o saber de operação crescesse em volume de conhecimentos necessários e diversificação de conteúdos, de modo a poder ser, hoje em dia, até tomado e mesmo criado isolado do momento da produção dos trabalhos e apropriado pela forma ciência de produzir conhecimento. Em outros termos, um conhecimento do tipo teoria. Diremos uma teoria sobre práticas ou modos de praticar, a que alguns autores chamam de teoria científica das técnicas ou tecnologia - a ciência das técnicas (Gama, 1986; Lenk,1990); para outros, simplesmente ciência, sem diferenciar as ciências tecnológicas das ciências básicas, em razão da grande aproximação histórica entre ciência e técnica (Granger, 1994).

Esse é o resultado de um de longo transcurso histórico. A partir dos séculos XV e XVI, processa-se uma grande alteração das conexões entre ciência e técnica, envolvendo essencialmente a questão do valor da prática e suas operações, bem como o valor das necessidades materiais humanas. Alteram-se, pois, as relações entre a filosofia e a ciência, o trabalho manual e o intelectual, a teoria e a técnica. Em síntese, abandona-se a concepção de ciência como verdade desinteressada da perspectiva das necessidades materiais - busca que nasce apenas após o atendimento das coisas necessárias à vida. (Rossi, 1989:17) - em prol de uma busca que nasce para esse atendimento, cujo modo mais imediato ou não de fazê-lo também representa distintas situações históricas, como a modalidade contemporânea de conhecimentos do tipo ciência (mais tecnológico) ou a vigente ao longo de todo século XVIII e parte do XIX. Neste mesmo movimento, ocorre uma grande alteração no sentido social do trabalho e da técnica, que culmina, no 
século XIX, na enorme importância do trabalho para a conformação da vida social.

É interessante notar que a rearticulação ciência-técnica corresponde ao movimento que redispõe socialmente os artistas, os experimentadores e engenheiros, os médicos, em especial os cirurgiões-barbeiros, os artesões e os trabalhadores manuais, camponeses e posteriormente fabris, estabelecendo novas configurações e hierarquias entre as artes mecânicas e as liberais. Este movimento cinde, separa e reagrupa distintas ações, compostas anteriormente de outro modo, mas tidas em seu conjunto como intervenção manual, por oposição a atividades ligadas aos saberes eruditos. Por exemplo, os artistas e arquitetos passam da condição de artesões a de burgueses e intelectuais; são cisões de antigas corporações e novas constituições de arranjos de interesses e representação coletiva (Rossi, 1989). Ao mesmo tempo saberes técnicos são inscritos em conhecimento erudito até que a ciência moderna se aproprie plenamente dos saberes de ofício das técnicas e isole, por sua vez, já no movimento dos séculos XVIII e XIX, de um lado o trabalhador manual da grande indústria - o sem saber - e de outro, o artista, cujo saber criativo e livre é sem importância, porque não seria "útil”.

Assim, diferentemente de outros momentos históricos, em razão da existência da ciência moderna e de suas relações com o conhecer humano, nos aproximamos desta ciência já como conhecimento de natureza técnica em todas as suas atuais conotações. De tal modo este caráter técnico está associado à teoria da ciência, que a esta tendemos a valorizar tanto mais quanto mais representa uma utilidade necessária, resposta útil às necessidades da vida, ou, como Ayres (1995), razão tecnológica regendo a produção de conhecimento.

Neste processo a própria técnica revestiuse de ciência, tendencialmente expulsando saberes de outro tipo como conhecimento para intervenções (Habermas, 1990). Esta associação atual da técnica com a ciência, evita valorizarmos saberes práticos e artes técnicas diversos da teoria e da técnica científica moderna. Duas operações conceituais podem ser registradas nesse sentido: de um lado, a valorização do âmbito prático para o conhecimento teórico, erudito, sem que contudo este deixe de ser teoria. De outro lado, o esvaziamento da técnica, como forma de sua "valorização" moderna, na direção de um procedimento prá- tico, mera aplicação da ciência ou seu braço mecânico para a ação, desqualificando seu âmbito próprio de produção de conhecimento enquanto ação. Essas concepções nos ocultam a dialética saber-ação e, principalmente, a existência de múltiplos saberes, em diversas formas de agir técnico, na passagem da ciência para o trabalho.

Entre a ciência e o trabalho, apontamos o concurso de dois saberes: o saber operante, também denominado tecnológico, que orienta a aplicação da ciência, da perspectiva da racionalidade da ação no trabalho; e o saber prático, em que, na atividade do trabalho, o próprio saber tecnológico se testa e se enriquece. Observemos que a correção prática pode exercer-se sobre a tecnologia (saber tecnológico), mas também sobre o dado científico.

Estamos chamando atenção para a re-criação de todo saber no ato do trabalho (Schraiber, 1993; 1995;1997) ${ }^{7}$. O saber não esgotará nunca sua recriação quando em ato; não se esgotam as mudanças que qualquer agente introduz em sua ação, ainda mais se considerado o caráter reflexivo de certos trabalhos tal qual o trabalho em saúde (Offe, 1989), por mais que esteja sendo mecânico o trabalho.

Por outro lado, também sabemos que há situações técnicas em que a exatidão do saber científico e tecnológico não é tão completa assim, e sequer pode sê-lo. É o caso próprio da ação em saúde e em particular, mas não só, do cuidado médico. Nestes casos, o saber prático, da experiência, muitas vezes bastante sistematizada e outras estudada cientificamente (como nos ensaios clínicos, na medicina baseada em evidências) mostra os "ajustes" clínicos dos casos ou de cada caso à norma geral esperada. São ajustes que buscam minimizar o efeito das incertezas dos fenômenos vitais, que não podem ser totalmente previstos ${ }^{8}$. De outro lado, também sabemos dos contextos da produção do trabalho, em que a própria precisão do saber tecnológico e da ciência encontrarão limitantes de operação.

Recriar, assim, é sempre fato do âmbito prático e o saber prático fornece esse tipo de conhecimento que, se pode até mesmo corrigir o conhecimento teórico, vai mostrar outros caminhos da ação, que o saber tecnológico sistematiza, garantindo a "tecnicalidade" do ato de trabalho.

Ao planejamento do trabalho e sua gestão caberá, pois, lidar também com este componente do trabalho, ao mesmo tempo que deve 
zelar pela qualidade do produto objetivo do trabalho, lidando com a racionalidade técnico-científica de sua operação. Articular esses componentes do trabalho em saúde no momento que é processo particular e concreto em serviços dados é um dos problemas da gestão: conhecer melhor essas relações será, sem dúvida, uma questão.

\section{Trabalho, sociabilidade e interação}

Se técnica e trabalho (no sentido humano-genérico) são a forma propriamente humana de produzir respostas a necessidades através de procedimentos intencionais de alteração da natureza, também devemos lembrar que são modos de construção da vida social, formas de sociabilidade, surgindo o trabalho como expressão da própria socialidade do homem. Deste modo, as finalidades dos trabalhos são correspondentes à construção ético-política do modo social de viver.

O saber tecnológico ao projetar o modo de executar o trabalho, viabilizando a ação estratégica, realiza a intencionalidade de natureza técnico-científica, consolidando a ação técnica e, por meio desta técnica, realiza, simultaneamente, a natureza ético-política da vida social $^{9}$.

Mas estabelecendo-se na esfera da referida tecnicalidade do trabalho, esse saber operante pode deixar pouco visível essa complexidade da dimensão intencional para a ação. A intenção parece respeitar apenas a realização do científico, obscurecendo sua qualidade de ser também a realização de projeto social: razões e propósitos histórico-sociais contidos no interior do saber-fazer técnico, ou o "como agir” no exercício da profissão. Será com base nisto, pois, que toda ação de trabalho, mesmo que examinada pela perspectiva de ato produtor de produtos dados, pode e deve ser reconhecida (e estudada) como intenção técnica, ética e política em ato.

Da perspectiva do agente do trabalho, tal intenção exterioriza nesse agir (e no ato do trabalho) a inscrição de cada profissional na normatividade social, articulando o indivíduo às normas da sociedade (Ayres, 1995) ${ }^{10}$.

Se não tornarmos clara mais esta relação em nosso entendimento de toda a questão do trabalho, retiramos do agir seu complexo de intenções e o exercício de sujeito deste agente da técnica, para esvaziar o ato produtivo e o agir profissional - que são duas perspectivas distintas de se abordar o trabalho - em um tecnológico de senso muito restrito, um "como" se faz destituído de "para que" ou "por quê" assim o fazemos. Note-se que estes últimos parâmetros revelam as origens do ato, as raízes históricas do trabalho e do agir técnico do profissional, ao apontar as necessidades e as finalidades sociais a que o ato se relaciona. Enquanto que o "como" revela a expressão com que se torna visível a ação, o que, se tomado como a representação completa da ação, pode nos mascarar a importância das origens e das razões da ação, elementos-chave para nosso entendimento da intencionalidade do trabalho no plano ético e político de seu projeto. Além disso, na abordagem dos profissionais em situação de trabalho, mais do que abordar o trabalho em si como ação estratégica, as origens e as razões da ação são igualmente elementos centrais para conhecermos os sujeitos em ação. Sujeitos expressando-se no e através do trabalho e o trabalho como interação social.

Este esvaziamento de sentido ocorre quando locamos nossa problemática de conhecimento apenas relativa às questões da operação do trabalho. Por exemplo, ao tomarmos a tecnologia por si mesma ou por seu representante maior - o equipamento, a máquina - isolados da finalidade social do processo de trabalho. É comum concebermos que conhecemos as razões ou finalidades da ação (o porquê e para que) quando conhecemos a operação (o como). Assim à pergunta: por que cortamos, montamos, pintamos, etc... o aço?, remetida por exemplo à fabricação de motos, responderíamos para ter motos; ou à pergunta $p a-$ ra que cortamos, montamos, pintamos o aço, etc..?, igualmente será respondida: para ter motos. A indagação a que me refiro no texto é, porém, não relativa ao como ou à operação, senão a seu produto: por que e para que motos? cuja resposta remete à origem social e histórica da ação, quando então produzir motos se cria como necessidade da vida cotidiana ${ }^{11}$.

Todas essas questões são relevantes para lidar com a técnica e os processos de trabalho. E são tão mais relevantes diante dos sentidos contemporâneos da técnica e do trabalho, em especial a partir de suas crescentes complexidades nas sociedades modernas, tal como se verificou sobretudo ao longo do século XIX e da subseqüente tendência de passarmos a ver quase todos os atos da sociedade como trabalho, ou ao menos sob suas referências ${ }^{12}$. 


\section{Planejamento e gestão; técnica e trabalho}

Uma incursão pelas diversas proposições de planejamento em saúde que ocorreram na América Latina nos mostra que quase todas elas, possuem uma rica e às vezes bem completa exploração de técnicas. São proposições com alto teor prescritivo e com orientações bastante apuradas do agir (em planejamento). E talvez por essa característica é que autores como Testa (1992) propõe para suas reflexões de caráter mais teórico e enunciadora de princípios gerais para a ação, não a noção de planejamento estratégico mas a do pensar estratégico ${ }^{13}$.

É interessante observar que estamos tratando da ação de planejar que produz uma peça propositiva que é o plano. Este contém um projeto futuro de ação, sendo esta ação igualmente uma proposta para articular outras ações, isto é, uma futura organização e formas de gerenciamento do trabalho produtor dos serviços. E, de outro lado, através das propostas de gestão - que podem ou não pertencer ao plano - produz tecnologias de operar a organização do trabalho proposta. Tais tecnologias serão a gestão: um saber capaz de conduzir a planejada forma (organização) de realizar o trabalho em saúde.

Se o plano é uma orientação para a ação, uma proposição de otimização dos trabalhos de outros, que não o do planejador, essa modalidade de atuar é como se fosse um trabalhar sobre trabalhos, fundado na necessidade de racionalização do trabalho produtor direto dos cuidados, pois a finalidade do planejamento é instruir e a da gestão é processar tal instrução sobre processos de intervenção em saúde. Planejamento e gestão realizam ação estratégica quanto ao trabalho em saúde.

Essa compreensão não é absolutamente nova. Basta relembrarmos as noções clássicas de uso corrente na administração de "atividadesmeio" e "atividades-fim". Ora chamamos atenção para o seu tratamento como técnica e trabalho. Assim, se um trabalho de produção de determinados bens ou serviços corresponde à forma socialmente dada de responder a necessidades diretas sobre esses bens ou serviços, o planejamento representa a perspectiva de racionalizar (e otimizar) essa produção. Será, pois, indiretamente satisfação das mesmas necessidades e diretamente satisfação das exigências de melhor produtividade do trabalho produtivo para o qual é necessidade direta.
Planejar assume, desse modo, imediatamente as características de ação técnica, mais precisamente, estratégia racionalizadora e saber prescritivo, da perspectiva de tal ou qual política a realizar: ação estratégica para interesses do Estado, da empresa.

Por isso o planejamento, como disciplina e prática, busca criar e aprimorar, experimentar e realizar tecnologias de poder.

Ao ser o braço da política que opera práticas racionalizadoras para fazer com que se realizem projetos sociais dados, através da produção social, em que se inclui a da assistência à saúde, o planejamento expressa-se como um saber operante, tecnológico, cuja ação estratégica está em realizar aquele projeto. Inspirados na idéia foucaultiana do poder como a ação de determinados sujeitos sobre as ações de outros (Dreyfus Rabinow, 1995), afirmaremos que o planejamento e gestão, "tecnicalizando a política", desenvolvem saberes operantes de sua ação que representam tecnologias de poder, ferramentas de exercício de poderes, porque facultam modos de agir sobre as ações de outros. Relembremos que, no caso do gestor público, tal poder reside em sua legitimação social como agente do Estado, gerente (agente da empresa) e, ainda, profissional da saúde (agente da ciência).

O planejamento é, pois, ele próprio também uma técnica, mas uma técnica que sabe sobre o modo de dispor, arranjar e processar outras técnicas. Quando na prestação direta dos serviços para a população em geral, o planejamento apresenta-se como um trabalho de gestão, trabalho que se ocupa dos outros trabalhos em saúde: organizando e processando essa organização de modo a que a assistência produzida para a população realize princípios ou pressupostos que instruem o agir, primeiro, políticos, e segundo, técnico-científicos ${ }^{14}$. Por isso a esfera própria do planejamento e gestão está, pois, em articular o político com o técnico-científico na produção dos cuidados assistenciais em saúde.

Não será demais lembrar que esses requisitos da gestão representam aquela situação de gerente/gestor antes comentada: esse agente deve articular em sua prática profissional, nas técnicas que conhece para propor estruturas e para operá-las, a racionalidade do ato médico e sanitário e os conflitos que aí se inscrevem relativos às demandas; as razões de Estado e os conflitos que aí se inscrevem quanto às necessidades sociais e à justiça social; as con- 
quistas de direitos em saúde, como as da reforma sanitária com seus princípios (universalidade, eqüidade, por exemplo) e diretrizes práticas (descentralização, participação, por exemplo) e os conflitos que aí se inscrevem com os sistemas já existentes de saúde e suas modalidades de organização institucional.

Em razão disto, explicitar melhor toda essa passagem do político ao assistencial, e de que maneira isto implica articulações entre as diretrizes políticas, os preceitos éticos e a normatividade dos processos de trabalho, passa a ser uma questão. Também porque temos defendido a idéia de que essas passagens não estão suficientemente estudadas e claras para os projetos de intervenção, talvez por conta de certa familiaridade com o técnico-científico que detemos por nossa própria formação de profissionais da saúde. Tendemos a tomar este plano como um conhecimento já dado, sem atentarmos para o fato de que, como vida prática, ele não está dado, mas precisa ser estudado como saber aplicado e recriado na ação do trabalho, em seu cotidiano particular. Assim, compartilhando com o princípio etnográfico de que nem tudo que é familiar, é conhecido, e que para conhecê-lo, é mister tornar o familiar algo estranho, exótico (Matta, 1978), uma problemática importante será a desta relação entre o planejamento e o trabalho em saúde (Schraiber, 1990;1995).

Claro está, de outro lado, que trabalhos como os de planejamento, administração, gerência ou gestão surgem como necessidade do processo de produção, em razão da complexificação desta produção, como é o caso da especialização do trabalho e da produção em escala. Neste contexto, a fragmentação do processo produtivo exige um trabalho de controle e supervisão que coordene a recomposição de conjunto. Esta será a racionalidade deste trabalho como ação estratégica, realizando sua tecnologia de poder. Nestas circunstâncias planejamento é sinônimo de gerência ou administração.

Mas, tal qual já dito, há outra situação em que aquele trabalho ganha conotações mais amplas: é o caso do administrador da coisa pública, no interior dos dispositivos e equipamentos de governo. Aqui, o gestor de serviços é também um implementador da política de Estado, ressaltando-se a natureza política (de prática imediatamente política) da sua ação, mesmo como supervisor ou controlador técnico da recomposição do trabalho coletivo (ge- rente). Um agente deste tipo não é só o executor da política da empresa em que é o gerente, mas situa-se como parte da formulação de Estado, um formulador também de políticas (Merhy, 1992).

Em realidade a noção de planejamento associa-se historicamente a essa "administração" de macroestruturas, a planificação social, ao passo que no plano da prestação direta dos serviços, associa-se à noção de gerência, que além de planejar inclui outras ações, entre elas as da avaliação como instrumento tanto do controle e supervisão técnicos, quanto instrumento para agir nas interações.

Ocorre que na saúde, mas não só, este formulador é freqüentemente escolhido por seu saber de trabalhor técnico-científico. Vale dizer, dentre os profissionais da saúde e mais usualmente dentre os médicos. Formulará políticas, então, ou criará tecnologias de realizar as políticas, com base em uma específica combinação: as questões de Estado articuladas com as que conhece como profissional da saúde. Este agente porta duas competências que correspondem a autoridades em conflito. Carapinheiro (1993), mostra a tensão entre a autoridade médica e a gerencial, a primeira com interesses tradicionais da profissão e a segunda representando a organização moderna do trabalho profissional. Entre a situação racional-legal desta última e o poder médico legitimado socialmente, estabelece-se muito freqüentemente uma relação de oposição.

Sintetizadas ambas as exigências em um só personagem (Ribeiro, 1996), a superação do conflito corre dois riscos opostos. Primeiro, o risco da tecnificação da dimensão política deste trabalho na tecnoburocracia de Estado, quando o formulador se desqualifica como agente político e desqualifica a própria política. As críticas correntes sobre a técnica de programação local (Rivera, 1989; Merhy, 1995; Kon, 1997) apontam exatamente nessa direção: o esvaziamento da dimensão política, como planejamento de política pública. Este esvaziamento pode se dar na direção da normatividade da medicina ou de seus saberes (epidemiologia, clínica), mas também na direção ou combinados, por vezes, ao desenvolvimento de tecnologias do político também reduzida à sua própria tecnicalidade: a racionalidade produtiva com base na econometria da eficiência e eficácia "puras"15. Neste caso, a tecnicalidade do planejamento e da gestão assume o sentido de um fim em si mesmo, e suas tec- 
nologias não são mais meios de realizar o político no técnico-científico. Mesmo formas não tão normativas ou clássicas de planejar não estarão fora deste risco, que é o da valorização primeira de sua própria tecnicalidade, ao invés dos princípios ético-políticos a que veio servir de saber operante ${ }^{16}$.

Em segundo lugar, há o risco oposto. Atuando estritamente conforme com os interesses do Estado e de suas organizações, invalida-se como portador de autoridade no seio dos profissionais, por não mais representar seus interesses e necessidades, invalidando-se, boa parte das vezes, também como autoridade junto à população em geral, pela forma como a autoridade médica incide nesta. Podemos ver no atual modo pelo qual o próprio Sistema Único de Saúde (SUS) emerge como questão de Estado, parte desse processo.

Esta consideração necessita de maior exame, pois envolve uma representação de natureza mais complexa da autoridade profissional, visto estar em jogo também uma cisão interna às próprias corporações profissionais. Trata-se da especificidade de cada saber profissional, de um lado, tomando de modos distintos e sob valores diversos as necessidades da população e formulando também de modo variado o que são as necessidades dos profissionais na produção de seus trabalhos. Além disto, os próprios profissionais detêm distintas visões entre si, também disputando hegemonias na política pública e nas políticas profissionais, quanto às suas competências, autoridades e poderes particulares, no conhecido conflito entre as diversas "corporações" da saúde.

Esses riscos podem ser minimizados, quando o formulador detém a percepção de sua dupla, por vezes tripla inserção: a de técnico (da saúde no Estado) e a de político (de Estado na saúde), a que pode-se somar a de técnico de política (do gerente na empresa do Estado). E esta possibilidade além de representar um grande desafio ao próprio gestor em saúde, traz uma questão relevante de duas ordens para a área do planejamento e da gestão dos serviços: a complexidade tecnológica de seu próprio trabalho na saúde e os conflitos nas relações interativas que também perpassam esse trabalho, ele próprio ação estratégica e interação.

Essas duas ordens de questões serão apresentadas a seguir através de dimensões na produção dos serviços em saúde que são privilegiadas para apontar suas problemáticas, pois representam os planos em que essas questões são experimentadas como grandes impasses no cotidiano dos serviços: o trabalho em equipe e a relação entre gerentes e profissionais diretos do cuidado quanto à produção e uso das informações em saúde para a tomada de decisões.

\section{Trabalho em equipe; articulações técnicas e projetos assistenciais comuns}

A proposta e a prática do trabalho em equipe estão, ambos, o almejado e o realizado, relacionados a uma série de mudanças que vêm ocorrendo na oferta de serviços de saúde, tais como: a especialização do trabalho; a especialização das disciplinas científicas; a crescente incorporação de tecnologia; a institucionalização elitizadora e segmentadora da oferta de atenção à saúde; o caráter interdisciplinar dos objetos de trabalho em saúde; o valor ético e a diretriz política da atenção integral às necessidades de saúde do conjunto da população. Conjugam-se nesta aspiração ao trabalho em equipe, portanto, tanto a divisão dos trabalhos e dos saberes, quanto a necessidade de recomposição de suas ações.

Visto que as necessidades de saúde expressam múltiplas dimensões - social, psicológica, biológica e cultural, e que o conhecimento e as intervenções acerca desse objeto complexo - o processo saúde-doença - constituem um intenso processo de especialização, a nenhum agente isolado cabe, na atualidade, a possibilidade de realizar a totalidade das ações de saúde demandadas, seja por cada um dos usuários em particular, seja pelo coletivo de usuários de um serviço. Coloca-se, pois, a necessidade de recomposição dos trabalhos especializados, com vistas à assistência integral de saúde, seja de especialidades de uma mesma área profissional, seja de áreas distintas - multiprofissionais.

No entanto, a idéia de recomposição, na direção da integralidade da atenção, não tem se mostrado possível por meio da mera locação de recursos humanos de diferentes áreas profissionais nos mesmos locais de trabalho. A presença de variados profissionais realizando ações isoladas e justapostas, ou seja, apenas executadas lado-a-lado, sem articulação e sem comunicação, não permite realizar a eficiência e a eficácia dos serviços na perspectiva proposta da atenção integral. Esta requer uma modalidade de trabalho em equipe que traduza 
outra forma de conectar as diferentes ações e os distintos profissionais, no coletivo de agentes presentes à prestação de serviços.

Distinguimos dois tipos de trabalho em equipe: equipe agrupamento e equipe integração, distinção em que o segundo tipo se caracteriza pela articulação das ações e pela interação dos agentes (Peduzzi, 1998). A articulação seria resultante da intervenção ativa de cada agente dos distintos trabalhos envolvidos em dada produção de cuidados, no sentido de lidar com as conexões existentes, do ponto de vista objetivo formal, entre as ações ou trabalhos especializados. A interação como a ação comunicativa consistiria, por parte de todos os envolvidos, na busca do entendimento e do reconhecimento recíproco de autoridades, saberes e autonomias técnicas ${ }^{17}$.

Quanto à articulação das ações, trata-se de conectar diferentes processos de trabalho, visto que cada trabalho especializado constitui um processo peculiar com objetos, instrumentos e atividades próprias. A atividade ou ação profissional consiste no que pode ser observado concretamente do trabalho de cada agente, no entanto, expressa a lógica interna do respectivo processo de trabalho, ou seja, como já mencionado, uma certa relação entre o objeto sobre o qual incide a atividade e no qual o saber técnico instrumentaliza a ação para certo resultado ou produto. Portanto, a articulação das ações ou dos trabalhos requer, da parte de cada agente, um dado conhecimento acerca do trabalho do outro e o reconhecimento de sua necessidade para a atenção integral à saúde. Ou seja, a própria articulação das ações requer, ao menos, uma certa modalidade de relação entre os agentes, em que, ao menos algumas informações sejam trocadas, mesmo que não se estabeleça um agir comunicativo como interação.

Já pensar essa interação ou comunicação dos agentes da equipe, é pensá-la não somente como meio que permite estabelecer as correlações e os nexos entre as distintas ações, mas também como a construção de consensos quanto aos objetivos e resultados a serem alcançados pelo conjunto dos profissionais e a maneira mais adequada de atingi-los. Ou seja, a interação dos agentes permite a construção de um "projeto assistencial comum" à equipe de trabalho - onde e como chegar no que se refere às necessidades de saúde dos usuários.

No entanto, ainda como nos mostra Peduzzi (1998), nem todas as formas de relacio- namento conduzem à interação comunicativa, em que cada estratégia de ação profissional e a racionalidade de seus trabalhos é conhecida, dialogada e negociada como prática comum. O trabalho em equipe é o trabalho que se compartilha, negociando-se as distintas necessidades de decisões técnicas, uma vez que seus saberes operantes particulares levam à bases distintas de julgamentos e de tomadas de decisões quanto à assistência ou cuidados a se prestar.

Nesse sentido, tal concepção de trabalho em equipe assenta-se em algumas questões prévias e que são também questões no planejamento e gestão dos serviços de saúde.

Primeiro, vamos considerar que os diversos trabalhos especializados expressam relações de complementaridade e interdependência entre si, não constituindo trabalhos independentes, visto serem resultantes de um processo de divisão do trabalho que se dá a partir de uma prática originária e fundadora da técnica científica moderna na área da saúde a prática dos médicos. No entanto, esse caráter complementar não se traduz automaticamente em articulação das ações, visto que estas implicam numa intervenção do agente que coloca em evidência as conexões entre os distintos trabalhos. Vale dizer: as conexões entre as ações são objetivas, mas para refletirem-se em interação, devem ser expressas pelos agentes dos trabalhos para que, ativamente, sejam tornadas públicas e alvo de uma atenção desse mesmo plano, a esfera gestora dos trabalhos. Portanto, faz-se necessário estimular, reconhecer e valorizar a disponibilidade dos agentes para operarem articulações entre os trabalhos executados pelas diferentes áreas.

Mas, em segundo lugar, a referida complementaridade e interdependência entre os trabalhos especializados que compõem a equipe de saúde está freqüentemente em tensão com a autonomia técnica que os profissionais buscam ampliar. Por um lado, os agentes buscam uma autonomia tal como reza a tradição na área da prática dos médicos e prática do tipo liberal, quando o profissional que já trabalha isolado e como prestador independente de serviços, procede aos julgamentos e tomadas de decisão técnicos por si mesmo e baseados em sua autoridade individual. Isto implica na atual prática especializada, julgamentos e decisões, sem nenhuma troca com os demais agentes. Claro que esta é uma retórica radical, pois seria exagerado falarmos em "nenhuma troca". 
Contudo, ainda que muitas interconsultas ocorram, sabemos também que dois procedimentos são freqüentes: ou realizar sem discutir o parecer do outro especialista, ou desconsiderá-lo, por completo ou submetido a seu próprio julgamento e decisão. Além do que é preciso também problematizar esses procedimentos da perspectiva das relações de poder no interior de uma equipe de trabalho, quando esta é multiprofissional, com profissões cujas autoridades são desiguais. Em realidade, trata-se da desigualdade dos poderes implicados nos particulares saberes das áreas profissionais, em que autoridades técnicas diferentes passam a significar poderes e valores diferentes, com conseqüente desigualdade na legitimidade de julgar e decidir no trabalho, criar e recriar a técnica.

Por outro lado, é curioso que em certas interconsultas informais, quando os especialistas detêm vínculos de confiança, mais que vínculos formais do sistema prestador em que se inserem, há mais chances de interação e comunicação para o "projeto comum", muito embora, como nem sempre se trata de uma mesma equipe de trabalho, esta interação não se dá como um trabalho de equipe. Não há neste caso um projeto de trabalho a se realizar, mas como uma cooperação profissional, sem conexão com a produção concreta do trabalho.

Considerando-se, ademais, que os profissionais precisam reconhecer a complementaridade e proceder ativamente à articulação das ações, o que se têm como questão é a forma de realizar as necessárias autonomias técnicas através dessa complementaridade e interdependência. Espera-se, aqui, um duplo movimento por parte da equipe de saúde, pois tanto a autonomia técnica dos profissionais quanto a articulação das ações, são necessárias para a eficiência e eficácia dos serviços. Movimento que requer o exercício da autonomia técnica de forma interdependente, autonomias reconhecidas e negociadas pelos distintos agentes, por meio de sua interação.

A descentralização da tomada de decisão e, mais uma vez, a flexibilidade da divisão de trabalho estão no âmago das questões colocadas pela equipe de saúde, pois, como o trabalho em equipe requer a interação dos agentes no sentido do entendimento mútuo, não cabe a intolerância às iniciativas individuais ou coletivas, nem o cumprimento inquestionável das relações hierárquicas e das regras técnicas do trabalho.

\section{Informação, registro, comunicação e trabalho}

A temática da informação - sua geração, registro e transmissão ou socialização - é uma questão articulada ao trabalho em equipe. A integração dos profissionais, trabalhadores de uma mesma equipe, pressupõe, sem dúvida, compartilhar informações, referidas não apenas aos usuários dos serviços, mas à população potencialmente usuária em geral, o que é uma referência mínima no sentido da construção de projetos assistenciais comuns. Do ponto de vista dos processos de trabalho e articulação de seu conjunto, tais informações devem ser ainda referidas aos desenvolvimentos efetivamente experimentados de produção dos cuidados, nos trabalhos especializados.

De outro lado, a troca de informações, se é peça chave da comunicação nas relações interativas, não recobre, de certo, todas as questões que antes referimos acerca dessa interação. Não obstante, um projeto de trabalho de base comunicativa, não se inicia sem prever práticas e instrumentos para tal e quais informações serão alvo desses procedimentos.

Além da equipe de trabalho composta pelos produtores diretos do cuidado, essa questão da informação articula outra "equipe" de trabalho: a que reune os produtores diretos do cuidado e os gerentes dos serviços. Através dela, podemos tomar a perspectiva articuladora dos trabalhos em um projeto comum, como objeto do trabalho gerencial.

Para cada uma desses agrupamentos de agentes em saúde (profissionais-profissionais; produtores diretos-gerentes), gerar informações, registrá-las e compartilhá-las adquire significados diversos, em razão do próprio sentido instrumental da informação dentro de suas respectivas técnicas na produção do trabalho. Isto porque, como já examinado, se a informação é um dos meios para a consecução dos objetivos de cada trabalho - o produtor de cuidados e o gerencial - esses trabalhos possuem diferentes objetivos a serem alcançados. E em seu interior distintas problemáticas relativas à informação passam a se colocar.

Em estudo recente, Sala (1998) mostra que da perspectiva do produtor direto - aqui exemplificado com o caso do trabalho do médico $^{18}$ - a informação e seu registro importam de dois pontos de vista: como base para o raciocínio clínico e a tomada de decisão médica; e como memória auxiliar do próprio mé- 
dico, para o seguimento dos casos. A informação comparece, obviamente, como um meio para a resolução do problema médicosanitário e que diante desse trabalho comparece na forma da demanda individual do paciente, consoante com a finalidade desse trabalho. O que significa a necessidade técnica de resolver o problema concreto e particular daquele caso, naquele momento.

Além disso, resolver o caso, é, de fato, compreendido pelo médico como sua atribuição individual, como já dito, reproduzindo a tradição do trabalho profissional dos médicos. Compartilhar essa responsabilidade, aceitando julgamentos e negociando decisões com outros profissionais - médicos especialistas de outras áreas e demais profissionais da saúde e, ainda, os cuidadores diretos como o pessoal de enfermagem, por exemplo - não é tomado como problema técnico e não se apresenta, portanto, como uma questão a que deve responder. Somente naquelas situações em que essa independência de ação gera conflitos radicais e impasses no prosseguimento da execução do projeto assistencial que ele formulou para o caso, alguma comunicação em reconhecimento da complementaridade no trabalho surge como questão tecnológica e passa a ser elemento de sua técnica.

Dessa perspectiva estão ausentes quer a necessidade de informações que insiram o caso em grupos populacionais, a não ser para denotar o estilo de vida individual e as características pessoais dentro disso, quer a necessidade de avaliar diretamente a situação grupalpopulacional referida ao problema médicosanitário em pauta. Também estarão ausentes, no sentido do trabalho em equipe, as necessidades quer de registro de informações que apresentadas à consulta médica são relevantes a outros trabalhos, quer o aproveitamento na consulta do registro de outros trabalhadores especializados, e quer, ainda, de linguagem compatível com trocas comunicacionais.

Todas essas questões abandonadas como tal pelos produtores diretos, como se sabe, podem ser problemas do gestor, quando inserido em contextos de políticas de saúde que valorizem essa atuação, como no caso do gestor do SUS. Também estamos dizendo com isso que tal ou qual informação faz sentido tecnológico para esta ou aquela técnica, mas não são necessidades tecnológicas iguais e constantes para todos os profissionais e trabalhadores em saúde.
Para o produtor direto dos cuidados, o encontro de linguagem adequada para o registro-caso e registro-memória pessoal, e o encontro de uma hierarquia de dados a serem registrados, é sua problemática específica. Se isto possui alguma disciplina de ordem científica que se encontra em tratados de clínica (Dalmaso, 1998), no sentido comunicacional e interativo entre profissionais especializados, esta será uma recriação do saber tecnológico no exercício prático de suas orientações. E até para amparar tal recriação, em alguns serviços o registro padronizado serve de ponto de partida. No entanto, se a linguagem médica já não é mais comum entre os médicos, pois as áreas especializadas já cunharam linguagens específicas e de domínio restrito a seus especialistas, como mostra Atkinson (1995), o registro padronizado só encontra eco na tecnologia do produtor direto quando porta idêntica linguagem específica. Caso contrário, mesmo o padronizado sofre recriações, como mostra Sala (1998).

Temos, assim, da perspectiva comunicacional, uma ampliação dessa possibilidade entre profissionais de mesma área e uma maior dificuldade entre o trabalho multiprofissional, o que equivale a dizer que para o produtor direto, quando há preocupação interativa, deixando a informação e seu registro de terem caráter de memória estritamente individual e sendo instrumento de trocas de informações, isto só ocorrerá para as informações pertinentes senão ao caso individual, aos casos da especialidade, sem que tal procedimento deixe de ter o significado tecnológico de registrocaso.

Já diante da preocupação organizativa de integração entre profissionais no trabalho em equipe multiprofissional, e da preocupação avaliativa, como é a necessidade tecnológica do trabalho gerencial, a informação melhor é aquela que mais recobre a diversidade dos casos e do conjunto das operações dos trabalhos, para além das clássicas informações acerca da produtividade do trabalho e sua resolutividade em termos médicos e sanitários, para o conjunto dos casos. Primeiro, estará presente, aqui, sempre a preocupação de conjunto; segundo, a preocupação articuladora dos trabalhos, podendo a esta somar-se a percepção e conseqüente preocupação na esfera comunicacional e interativa, no sentido de desenvolver formas de trabalho efetivamente compartilhado. A necessidade tecnológica deste particular traba- 
lho, portanto, contrasta em vários pontos com a do trabalho produtor direto dos cuidados.

A isso acrescente-se o já mencionado fato de que gerentes de serviços pertencentes ao SUS, por exemplo, encontram-se diante de necessidades tecnológicas advindas de sua representação como gestor das questões da saúde pública. A gerência compromete-se, nesses serviços, não somente com aquelas ações tradicionalmente relacionadas ao campo da saúde pública (tais como vacinação e vigilância epidemiológica), mas destaca-se a marcada preocupação com a assistência individual. Neste sentido, a atividade gerencial está presente como ordenadora e controladora das ações médicas: a padronização dos registros, a formulação e implementação de diversas modalidades de atenção individual e em grupos de usuários dos serviços, as padronizações de condutas para diagnóstico e terapêutica, a supervisão técnica dos atendimentos, entre outros, são momentos presentes no cotidiano desses gerentes. Mas os médicos, como dissemos, tendem a desqualificar aquela perspectiva gerencial e sanitária no momento em que tomam a tarefa de intervir e resolver o problema do indivíduo que se apresenta à consulta médica.

Diante dessas divergências, dois tipos de lacunas terminam ocorrendo na geração das informações, mas principalmente em seus registros: uma que desqualifica a informação pertinente à atividade gerencial, outra, que reduz a anotação do caso a breves referências biomédicas que implicitamente justificariam a tomada de decisão médica.

Para o produtor direto, informações do tipo gerencial são tidas como apenas uma tarefa mecânica adicional, com a qual raras vezes sentem-se dispostos ou motivadas a colaborar. A nosso ver, uma melhora nesta direção é dependente do encontro de um sentido tecnológico a esse agente para tal atividade, exigência que se coloca para os formuladores das políticas públicas ou políticas institucionais e do planejamento dos serviços, além dos gestores. Essa questão é problemática a ser, certamente, melhor conhecida.

Para o gerente, despreocupado com a técnica desse produtor direto - ou como já dissemos, imaginando-se suficientemente instruído acerca dessa técnica, por familiaridade de capacitação profissional - não se coloca como exigência pensar elementos do registro facilitadores da "memória do caso" ou facilitadores da tomada de decisão médica. Isto é, não se coloca pensar uma linguagem e formas de registro que aproxime a sua necessidade de conhecer a população usuária e a necessidade clínica de conhecer o caso, a não ser os códigos bem estabelecidos pelos tratados clínicos, mas que apenas recobrem a dimensão biomédica da informação. É nesse sentido que, em situação de trabalho mais especializado até observamos convergência de objetos de interesse entre a ação gerencial e a do trabalhador direto, em especial o médico, no sentido da abordagem da doença no indivíduo. Também é de se notar, diante do fato de que o trabalho gerencial dirige-se à organização dos outros trabalhos, que em razão daquelas convergência, diminuem os conflitos entre esses trabalhadores: a atividade gerencial ganha o sentido do manejo de recursos, e, simultaneamente, de uma "liderança profissional". E isto é diferente do que ocorre nos serviços voltados à saúde pública, em que os contrates das técnicas e necessidades tecnológicas dos trabalhos são mais polares (Sala, 1998).

\section{Avaliação e trabalho; supervisão técnica e interação}

As atividades de avaliação mais freqüentemente exercidas pelo gerente são as voltadas para a verificação das metas mais gerais do plano e administração de recursos. Se estas são dimensões evidentemente importantes do trabalho da gerência, são também, por outro lado, limitadas na sua capacidade de dialogar com o trabalho direto. Levantamos aqui, a possibilidade, aberta por diversas correntes do campo da avaliação em saúde e por diversas experiências práticas de gestão do SUS, de entender a atividade avaliatória como potencialmente capaz de lidar e promover algumas das dimensões do trabalho que destacamos acima.

A corrente de avaliação mais conhecida, quando se trata de serviços assistenciais de saúde, é a da avaliação e garantia de qualidade, representada, principalmente, nos trabalhos clássicos de Donabedian. Não nos deteremos aqui em analisar a origem do inegável conflito entre a necessidade de autonomia do ato médico, de um lado, e a necessidade de controle social (ou accountability), que move os processos de avaliação da qualidade. (Schraiber \& Nemes, 1996). Gostaríamos de destacar aqui um outro aspecto: a potencialidade inscrita nesta relação. 
Os mecanismos mais tradicionais de garantia e avaliação da qualidade técnica do cuidado são, de fato, com muita freqüência, tomados pelos profissionais como, no mínimo, constrangedores, quando não como persecutórios e punitivos. Muito embora os teóricos da qualidade afirmem que mais importante que achar o culpado é achar e analisar o erro, até hoje os controles de qualidade mais tradicionais tendem, no mínimo, a ser restritivos, estanques e não vinculados a outros níveis da organização (Malik, 1996). Tanto esta noção punitiva têm base real, que há um crença disseminada de que é mais fácil trabalhar com qualidade no setor privado do que no setor público, justamente pela relativa impunidade dos trabalhadores no setor público (Malik, 1992).

Não cabe aqui analisar esta questão, mas assinalar que o abandono do caráter punitivo destes mecanismos, a assunção de que falhas são inevitáveis e de que ninguém erra por prazer são a base da lealdade da organização para com seus funcionários (Malik, 1996). E, evidentemente, são o ponto de partida para uma forma de avaliação que se pretenda dialógica entre a gerência e o trabalhador direto.

Claro que a declaração desta intencionalidade não é o bastante. O trabalhador da saúde é hoje, no serviço público, submetido a uma relação péssima como o trabalho que se assenta nos constrangimentos às condições mínimas de trabalho, na ausência de perspectiva profissional, na perda substantiva de qualidade do trabalho e no trabalho embrutecido pela política da "falta" ou da "escolha de Sofia" (Machado, 1993).

A implementação de mecanismos de avaliação e controle da qualidade técnica do cuidado a partir de definições de qualidade de fato negociadas entre os profissionais e a gerência pode ser um mecanismo de resgate da profissionalização, do orgulho e da valorização do trabalho. Embora o trabalho dos profissionais em saúde, especialmente o do médico, permaneçam necessariamente dependentes de ajuizamentos pessoais e de decisões arriscadas, a transformação tecnológica da medicina (Schraiber, 1997) ampliou significativamente as possibilidades de controle "externo" da prática. A polaridade entre a autonomia técnica e a maciça utilização de técnicas matérias de diagnóstico e terapêutica, abre um grande espaço de "negociação" possível entre a singularidade do ato médico individual e seu controle técnico externo.
É como promotor e incentivador destes mecanismos que o papel do gerente enquanto "liderança (também) profissional" pode também consolidar-se; é aqui que o registro pode ser informação re-valorizada enquanto alimentadora do processo avaliativo.

Novamente neste ponto é necessário ressaltar que o simples estabelecimento conjunto de critérios, normas ou padrões de qualidade não será suficiente. Não nos referimos apenas às necessidades de retro-alimentação ou de discussão constante dos padrões, já suficientemente ressaltadas pelos teóricos da qualidade. Chamamos a atenção para a especificidade tecnológica da atenção primária e as dificuldades metodológicas que elas implicam para os processos de garantia e avaliação da qualidade. Para além dos problemas comuns às práticas ambulatoriais como, por exemplo, a difícil caracterização dos episódios de doença, grande volume de queixas mal definidas e a presença importante de condições crônicas (Palmer, 1988), agregam-se outras, destacando-se, principalmente, a complexidade da articulação de finalidades diversas como a atenção à demanda espontânea e à condições epidemiologicamente importantes, ou a da qualidade do cuidado individual e a cobertura adequada da população adscrita (Nemes, 1996; Starfield, 1992).

Esta última questão nos parece a que mais tensiona, ao nível tecnológico, o processo avaliativo: enfrentar a cruel oposição entre princípios éticos-normativos como o da universalização versus qualidade. Traduzida no discurso dos trabalhadores pela triste expressão: “aqui fazemos o mínimo”, esta oposição resulta na cisão entre os planos ético, político e técnico do trabalho, reduzindo o plano ético à características pessoais e paralisando, com freqüência, qualquer tentativa de negociação entre a gerência, empurrada à condição de responsável exclusiva pelo plano político, e o trabalhador direto, à condição de responsável exclusivo pelo plano técnico (Nemes, 1996; Schraiber \& Nemes, 1996). Somente com base no enfrentamento claro e negociado deste desafio será possível o diálogo acerca das definições de qualidade aceitáveis. Aqui, novamente, o papel do gerente é fundamental e só possível de exercer, se a gerência estiver, de fato, inteirada e "aliada" ao trabalho direto (Castanheira, 1996).

As questões de avaliação que tratamos até aqui, embora possam ser estendidas para al- 
gumas das atividades mais coletivas das unidades de saúde, envolvem especialmente as atividades individuais e, em particular o cuidado médico. De fato, o foco de avaliação e as técnicas avaliativas derivadas da corrente da qualidade são compatíveis com esta modalidade assistencial. Mas os serviços de saúde complexos, como os de atenção primária, envolvem processos de trabalho diversos. A avaliação precisa dar conta deste conjunto. E aqui aparece uma outra problemática. "Dar conta" do conjunto não será somente a soma da verificação de características desejáveis de cada processo de trabalho. Evidentemente, esta verificação pode constituir-se em etapa ou foco temporário da avaliação, mas não a esgota.

As "grandes" categorias avaliativas, operacionalidade e efetividade estratégica ${ }^{19}$, propostas para o trabalho em atenção primária (Sala et al., 1998) podem orientar metodologias capazes de integrar, na avaliação, os trabalhos parcelares e o trabalho coletivo. Articuladamente à qualificação estratégica das ações, há que se avaliar também sua qualificação comunicacional (Ayres, 1995; Sala et al., 1996).

A especificidade tecnológica desta modalidade assistencial complexa implica ainda uma outra questão avaliativa, conforme Nemes (1996). Questão essa, que deriva do fato de que no plano da proposição do trabalho ocorrem sucessivas reduções entre a escolha do objeto, seu recorte para o trabalho e o estabelecimento de padrões de operação e julgamento do trabalho. Na operação concreta do trabalho todos esses momentos são simultâneos, ocorrendo necessariamente uma reconstrução totalizadora daqueles níveis. A escolha, o recorte do objeto e os padrões de operação estão consubstanciados na ação do trabalho. Na avaliação, o trabalho pode ser apreendido apenas pelos padrões construídos a partir daquela redução sucessiva. Com isso, as práticas de avaliação apenas detectam contrastes entre os padrões explicitamente esperados e os operados, sem analisar a rede de reconstruções que no trabalho como um todo estão sofrendo as escolhas, as normas e os padrões. Isto porque a dinâmica do trabalho, ao implicar uma totalização, necessariamente põe à prova aquelas reduções.

Isto implica que se partirmos de processos de trabalho onde este plano de reduções já se encontra claro e validado poderemos ignorar ou ao menos abstrair parcialmente a escolha prévia e a normatividade emanada desta pró- pria escolha, avaliando imediatamente os padrões da operação técnica. Trata-se aqui de uma clareza de regras que, contudo, não evidencia a racionalidade de sua construção; esta já está dada e validada como "bem" tecnológico. De fato, há processos de trabalho onde essa racionalidade pode ficar abstraída, sem prejuízo para a validade da avaliação e para a aplicabilidade tecnológica de seus resultados. Trata-se neste caso de avaliar processos isolados de trabalho cujos produtos encontram-se bem estabelecidos. É bastante razoável admitir, por exemplo, a abstração presente na avaliação do cuidado médico tendo por base um padrão fixo de tratamento para uma dada doença. Quando porém, os padrões referem-se a processos complexos, de múltiplas dimensões articuladas, abstrair completamente aquela instituição implica necessariamente uma limitação na capacidade da avaliação em revelar a re-criação que o plano propositivo sofre na operação do trabalho.

Evidentemente não estamos defendendo que a avaliação seja capaz de rotineiramente promover uma argüição profunda do trabalho tal como se faz nas investigações avaliativas baseadas em "grandes" aportes teórico-metodológicos. Chamamos a atenção apenas para a necessidade do trabalho integral de superar as avaliações instrumentais referidas nas normas fixas da clínica e da epidemiologia, muito embora estas também possam jogar papel importante em específicos arranjos do trabalho. É preciso lembrar, contudo, que os processos de trabalho muito legitimados, tal como ocorre no trabalho médico individual contam com padrões já tão fixados e igualmente legítimos que assumem no trabalho a representação de imperativos tecnológicos, assentados sobre uma espécie de padrão máximo tão difícil de atingir quanto sempre presente na formulação do plano discursivo do trabalho. Defrontar-se com padrões diversos, fundados em outras normatizações, implicará conflitos de competência e de legitimação, incertezas éticas e técnicas e dilemas individuais profissionais para os agentes ${ }^{20}$ que serão revelados na avaliação.Torná-los claros e submetê-los à discussão pública, pode ser o papel mais interativo da avaliação. Cremos que as metodologias avaliatórias baseadas na linha do empoderamento (empowerment evaluation, conforme Fetterman, 1994; Rowe, 1997) poderiam, pela sua compatibilidade de sua proposta com as questões que levantamos, ser bastante úteis 
para a gerência, na condução do processo de avaliação.

\section{Trabalho e política pública: lembrando uma última questão}

Seria importante considerar de que modo as questões gerenciais aqui tratadas e as características dos gestores nesta modalidade de organização relacionam-se com as tendências atuais das políticas públicas na proteção social, entendendo a saúde como parte dessa política. Isto porque, em razão da atual globalização dos mercados, há a tendência a se adotar políticas que passem tanto a "desproteger" o trabalho e o trabalhador, quanto, no caso da saúde, a regular diretamente o produtor direto dos cuidados, interferindo imediatamente em seus processos de trabalho. E nesta situação caberia indagar como ficam os gestores que representam esse Estado, exercendo seu papel de administrador público. Vale dizer, como agente também das ações estratégicas do Estado quanto aos modos da prestação da assistência, com certos padrões de produtividade do trabalho, certas formas de valorizar o médico e a equipe, certos resultados a alcançar junto à população, certas relações e condições de trabalho na articulação do setor público com o privado.

Os pontos de partida para uma tal reflexão remetem às questões recentes das novas articulações Estado-sociedade (Gerschman \& Vianna, 1997; Costa \& Ribeiro, 1996), incluindo a problemática da responsabilidade social para com a prestação direta de serviços. Isto agrega às problematizações de poder no campo das políticas públicas, aquelas concernentes à dimensão ética na articulação dos interesses público e privado (Girardi, 1996), aí configurando-se a problemática do Estadoprovedor ou do Estado-regulador, como dualidade a ser estudada, tal qual mencionado ao início deste texto. Isto implica novas relações do setor governamental não só com a sociedade em geral, mas também com as organizações coletivas de interesse profissional, em particular, as corporações e seus arranjos ( $\mathrm{Ri}$ beiro, 1996).

É óbvio que, pelos limites do presente texto tanto quanto de nossas próprias indagações, deixamos aqui apenas o convite para esta discussão.

\section{Agradecimento}

Os autores deste texto correspondem aos que tendo ocupado ou ocupando a gerência do CSE Samuel Pessoa, fizerem deste recorte seus objetos de pesquisa, para o que contaram com a grande colaboração dos demais, docentes e sanitaristas pesquisadores do Centro, cujas linhas de investigação em muito contribuíram para a reflexão ora publicada. Agradecemos ao Prof. José Ricardo C.M. Ayres e à equipe: Alexandre Nemes Filho, Ana Flávia P. L. d'Oliveira, Ana Silvia W. Dalmaso, Angela M. de Lima, Diane D. Cohen, Ivan França Jr e Ricardo R. Teixeira.

\section{Notas}

1 A denominação Saúde Coletiva surge ao final dos anos 70, embora o planejamento e a administração em saúde fossem já parte de campos que se fundiram na saúde coletiva. O reconhecimento do planejamento e da administração como temática conjugada é deste período, pois se o planejamento é valorizado como instrumento de ação para o desenvolvimento da saúde nos anos 60, a administração pública e sanitária lhe é anterior, como temática da saúde pública.

2 Uma primeira investigação nesta direção encontra-se em Teixeira e Sá (1996).

\footnotetext{
3 Buscando aproximar essas questões tanto da perspectiva da ação social, quanto da produção teórico-metodológica, o estudo da implantação de programas e sua avaliação tal como em Hartz (1997), fornece uma rica discussão, em um recorte amplo e conceitualmente detalhado a esse respeito.
} 
4 Cabe lembrar a discussão que se encontra em Schraiber e Mendes-Gonçalves (1996), acerca do subdesenvolvimento do conceito de atenção primária e a pouca atenção que ganhou na saúde coletiva o desenvolvimento de tecnologias nesse nível, denotando que nossa comunidade científica e profissional concebeu a simplicidade das patologias e técnicas pouco aparelhadas como sendo o mesmo que a simplicidade de cuidado e assistência ao paciente, terminando por não distinguir a tecnologia/equipamentos e as técnicas biomédicas da produção de um trabalho de assistência. Com isto deixou de considerar a complexidade da atuação neste nível assistencial, em que patologias simples e demandas básicas envolvem trabalho complexo, pois os cuidados são, em sua esfera própria, também difíceis. Sobre o trabalho em saúde como sendo sempre "ato difícil" por envolver em todos os níveis de atuação "julgamentos complexos e decisões arriscadas", mesmo que mude a natureza do risco e das complexidades assistenciais, veja-se Schraiber (1997).

${ }^{5}$ Note-se que dizemos cuidados e serviços a serem produzidos na assistência à saúde, distinguindo esses termos; queremos conotar que se todo cuidado prestado é uma produção de serviço, nem todo serviço produzido é um cuidado, atenção e intervenção na forma individualizada de demanda e trabalho. Por outro lado, que produzir/consumir serviços, em especial cuidados, seja visto como um bem a mais, no e do mercado, é certamente uma forma conflitante de ver a questão da saúde como parte do dever de proteção social do Estado, e não menos conflitante por referência à perspectiva democratizadora da gestão à participação/controle popular, o que apenas colocamos aqui como problemática a ser melhor desenvolvida. Ela também incorre em conflitos importantes na valorização do próprio trabalho e de seu profissional, problema que tem se tornado mais visível para os médicos e em razão do crescimento das organizações empresariais do sistema supletivo de assistência, em especial no caso dos que atuavam em formas de produção tradicionalmente valorizadas, por exemplo o consultório particular, antes desse maciço movimento de credenciamentos (Schraiber, 1997).

6 Especialmente relacionados a nosso campo valeria a pena consultar, como produções nesta perspectiva mais conceitual e tendo por base referenciais diversos: Ayres (1995); Mendes-Gonçalves (1992;1994); Ribeiro (1995); Novaes (1996) e Dalmaso (1998).

7 O componente do processo de trabalho em que se realiza essa recriação, temos denominado, da perspectiva de decisão/ação do profissional como sujeito da técnica, de autonomia técnica. Ao tomarmos, como linha de pesquisa, o estudo acerca do cotidiano de trabalho, temos pesquisado a noção de autonomia profissional exatamente neste recorte, mostrando sua restrição no plano mercantil, quando vende seus serviços em mercado, e uma redisposição que atualiza o poder de controle da ação no âmbito do julgamento e tomada de decisão assistencial, no atual trabalho altamente tecnológico. Veja-se também Ribeiro (1995) e Peduzzi (1998).

8 Distinguimos, aqui, o conhecimento científico que funda a técnica do saber prático da experiência profissional, do saber tecnológico que orienta a atividade do trabalho (Schraiber, 1997). Ver a respeito também, Dal- maso (1998), que sistematiza tais distinções, ao estudar as mudanças na produção do saber clínico.

9 Caberia aqui apenas relembrar que este é o fundamento da nossa compreensão do projeto ético-político da ação programática e de suas proposições para a operação do trabalho: saberes de cunho prático-operativo, saberes tecnológicos (Mendes-Gonçalves, 1994). Como projeto, a ação programática apreende de certa perspectiva ética e política as necessidades sociais; como saber tecnológico, propõe modos de fazer em modos de organizar o trabalho tecnicamente adequados às aproximações pretendidas das necessidades e sua satisfação.

10 O que também pode ser explicitado como uma externalização ou ato que torna objetiva a síntese que este agir representa: a articulação que este sujeito de projeto técnico (agente-sujeito técnico) realiza entre a objetividade da realidade social (e do trabalho) introjetada em sua própria subjetividade, enquanto sujeito sócio-histórico.

11 Veja-se discussão acerca do tecnológico como bem em si e desses deslocamentos em Ayres (1995).

12 Não entraremos aqui no debate sobre o atual deslocamento do trabalho como o centro da construção social ou o deslocamento da categoria trabalho para a melhor inteligibilidade da socialidade (Offe, 1989). Reteremos apenas a idéia de que o valor como categoria teórica não é o mesmo que o valor do trabalho como prática central de construção da socialidade, ao mesmo tempo que entendemos a necessidade de examinar melhor ambos os deslocamentos e seus sentidos concretos para a produção do conhecimento e para a intervenção social. Também é preciso contemplar as próprias mudanças do mundo do trabalho mais atual em que tais deslocamentos são observados. Quanto ao trabalho em saúde, ver Peduzzi (1997).

13 Ver também Giovanella (1990 e 1992) e Uribe (1995).

14 A priorização do político, neste caso, deve-se à situação objetiva deste lugar de gestor/gerente, claro. De outro lado, é bom lembrar, não estamos tratando da própria dimensão política que está contida nas ações técnico-científicas. O projeto de ação na intervenção técnica em medicina e saúde pública realiza sempre uma normatividade científica e outra de natureza ético-política, combinando conhecimentos técnico-científicos, interesses profissionais, valores éticos e tradições culturais dadas. A esfera política ora em pauta é aquela do contexto da ação médica ou sanitária, contexto organizador e dinamizador dessas ações, em unidades dadas de produção (ambulatórios, hospitais, etc.).

15 Aqui fica claro o excesso da tecnificação pois o cálculo de eficiência e de eficácia de um ato é rigorosamente técnico, em que se combina a técnica de cálculo de produtividade de um trabalho com a técnica do cuidado ou trabalho a ser produzido, sendo a combinação resultante tomada como um saber de operação em si mesmo e sem sentido social (pela cisão entre o financeiro e as demais necessidades sociais implicadas).

16 É interessante notar que há diversas outras tentativas de tecnificação de práticas sociais. Por exemplo, se- 
rá possível vermos na prática política as buscas de se encontrar formas estáveis de consecução de resultados simbólicos, mediante o recurso a saberes de operação determinados, tal como trabalhar imagens de candidatos a cargos públicos por meio de técnicas de comunicação de massa. Pode-se perceber nessas tentativas, uma espécie de tecnocentrismo, ou tecnologização do agir, por muitos colocado como o imperialismo dos meios (Gómez, 1990), por centrar a ação nos requerimentos da tecnologia material e dissolver os fins éticos em recursos tecnológicos de uma política tecnificada.

17 Retoma-se, aqui, a noção de autonomia técnica como a capacidade, competência e autoridade de recriação no saber prático dos conhecimentos científicos próprios de cada profissão, bem como dos saberes operantes indicativos quando no contexto de sua prática, conforme mencionado à nota 8 .

$18 \mathrm{O}$ estudo analisa como o significado da informação e seu registro, para médicos e gerentes, relaciona-se aos respectivos processos de trabalho em saúde, examinando, empiricamente, situações diversas da assistência

\section{Referências}

Atkinson P 1995. Medical Talk and Medical Work. Sage Publications Ltd, London.

Ayres JRCM 1995. Epidemiologia e Emancipação. Hucitec/Abrasco, São Paulo.

Carapinheiro G 1993. Saberes e Poderes no Hospital. Uma Sociologia dos Serviços Hospitalares. Afrontamento, Porto.

Castanheira ERL 1996. Gerência do Trabalho em Saúde: Desenvolvimento Histórico da Administração em Saúde nos Serviços Públicos do Estado de São Paulo. Dissertação de Mestrado. Faculdade de Medicina, USP, São Paulo.

Costa NR, Ribeiro JM 1996. Política de Saúde e Inovação Institucional. Escola Nacional de Saúde Pública, Fiocruz, Rio de Janeiro.

Dalmaso ASW 1998. Estruturação e Transformação da Prática Médica. Técnica e Ciência na Segunda Metade do Século XX. Tese de Doutorado. Faculdade de Medicina, USP, São Paulo.

Dreyfus H, Rabinow P 1995 Michel Foucault. Uma Trajetória Filosófica (para além do estruturalismo e da hermenêutica). Forense-Universitária, Rio de Janeiro.

Fetterman DM 1994. Empowerment evaluation. Evaluation Practice 15(1): 1-15.

Gama R 1986. A Tecnologia e o Trabalho na História. Nobel/Edusp, São Paulo.

Gerschman S, Vianna MLW 1997. A Miragem da Pósmodernidade. Democracia e Políticas Sociais no Contexto da Globalização. Fiocruz, Rio de Janeiro.

Girardi SN 1996. Flexibilização dos mercados de trabalho e escolha moral. Divulgação em Saúde para Debate 14: 23-32.

Gómez OG 1990. La Comunicación desde las practicas sociales. Cuadernos de Comunicación y Practicas Sociales 1, Universidad IberoAmericana, México (Número temático). ambulatorial: unidades básicas e ambulatórios especializados. Uma aproximação, também da perspectiva do processo de trabalho, do sentido da informação e registro para outros profissionais não médicos, em trabalho de equipe, pode ser encontrada em Peduzzi (1998).

19 A operacionalidade é a medida da possibilidade do trabalho realizar-se conforme a dinâmica processual estabelecida. Analisa, portanto, a operação do modelo de organização do trabalho. A efetividade estratégica é a medida do alcance dos resultados estratégicos apreensíveis nos usuários do serviço e/ou na população, atribuíveis às ações realizadas e inicialmente previstos por cada um dos programas ou conjunto de atividades. Seus indicadores variam conforme o objeto do trabalho ( $\mathrm{Sa}$ la et al., 1998).

20 Não estamos aqui aludindo ao caráter de incerteza próprio do processo de trabalho médico em geral mas à sobredeterminação desta incerteza técnica pela especial articulação do trabalho na integralidade, que gera dilemas de ordem diversa daquele do diagnóstico.
Granger GG 1994. A Ciência e as Ciências. Unesp, São Paulo.

Habermas J 1989. Consciência Moral e Agir Comunicativo. Tempo Brasileiro, Rio de Janeiro.

Habermas J 1990. O Discurso Filosófico da Modernidade. Publ. D. Quixote, Lisboa.

Habermas J 1994. Técnica e Ciência como Ideologia. Edições 70, Lisboa.

Hartz ZM de A 1997. Avaliação em Saúde: dos Modelos Conceituais à Prática na Análise da Implantação de Programas, Fiocruz, Rio de Janeiro.

Kon R 1997. O Planejamento no Distrito de Saúde: Estratégia e Comunicação. Dissertação de Mestrado. Faculdade de Medicina, USP, São Paulo.

Lenk H 1990. Razão Pragmática. A Filosofia entre a Ciência e a Praxis. Tempo Brasileiro, Rio de Janeiro.

Machado MH 1996. Os Médicos e sua Prática Profissional: as Metamorfoes de uma Profissão. Tese de Doutorado. Iuperj, Rio de Janeiro.

Malik AM 1992. Desenvolvimento de recursos humanos, gerência de qualidade e cultura organizacional. Revista de Administração de Empresas 32(4): 32-41.

Malik AM 1996. Qualidade em serviços de saúde nos setores público e privado. Cadernos FUNDAP 19: 7-24.

Matta R da 1978. O ofício de etnólogo ou como ter "anthropological blues", p. 23-35. In E de O Nunes (org.) A Aventura Sociológica-Objetividade, Paixão, Improviso e Método na Pesquisa Social. Zahar, Rio de Janeiro.

Mendes EV 1996. Uma Agenda para a Saúde. Hucitec, São Paulo.

Mendes-Gonçalves RB 1992. Práticas de saúde: processos de trabalho e necessidades, CADERNOS CEFOR Série Textos 1, Centro de Formação dos Trabalhadores em Saúde da Secretaria Municipal da Saúde (CEFOR/SMS), São Paulo. 
Mendes-Gonçalves RB 1994. Tecnologia e Organização das Práticas de Saúde: Características Tecnológicas do Processo de Trabalho na Rede Estadual de Centros de Saúde de São Paulo. Hucitec/Abrasco, São Paulo.

Merhy EE 1992. A Saúde Pública Como Política. Hucitec, São Paulo.

Merhy EE 1995. Planejamento como tecnologia de gestão: tendências e debate do planejamento em saúde no Brasil, p. 117-154. In E Gallo (org) Razão e Planejamento: Reflexões sobre Política, Estratégia e Liberdade. Hucitec/Abrasco, São Paulo.

Nemes MIB 1996. Avaliação do Trabalho Programático na Atenção Primária à Saúde, Tese de Doutorado. Faculdade de Medicina, USP, São Paulo.

Novaes RL 1996. Sobre a técnica. Manguinhos III(1): 2449.

Offe C 1989. Capitalismo Desorganizado: Transformações Contemporâneas do Trabalho e da Política. Brasiliense, São Paulo.

Paim JS 1993. A reorganização das práticas de saúde em distritos sanitários. In EV Mendes (org) Distrito Sanitário: o Processo Social de Mundaça das Práticas Sanitárias do Sistema Único de Saúde. Hucitec/ Abrasco, São Paulo.

Palmer RH 1988. The challenges and prospects for quality assessement and assurance in ambulatory care. Inquiry 25: 119-131.

Peduzzi M 1997. Mudanças Tecnológicas e seu Impacto no Processo de Trabalho em Saúde. Seminário sobre a Formação Técnica em Ciência e Tecnologia em Saúde, Escola Politécnica Joaquim Venâncio, Fiocruz, Rio de Janeiro. Mimeo.

Peduzzi M 1998. Equipe Multiprofissional de Saúde: a Interface entre Trabalho e Interação. Tese de Doutorado. Faculdade de Ciências Médicas, Unicamp, Campinas.

Ribeiro JM 1995. Trabalho Médico: Ciência, Arte e Ação na Conformação da Técnica. Tese de Doutorado. Escola Nacional de Saúde Pública, Fiocruz, Rio de Janeiro. 2 vols.

Ribeiro JM 1996. Estruturas tecno-burocráticas e instâncias colegiadas no SUS - uma abordagem dos fundamentos da política setorial, p. 51-68. In NR Costa \& JM Ribeiro (orgs.) Política de Saúde e Inovação Institucional, Escola Nacional de Saúde Pública, Fiocruz, Rio de Janeiro.

Rivera FJU 1989. Planejamento e Programação em Saúde: um Enfoque Estratégico. Cortez-Abrasco, São Paulo.
Rivera FJU 1995. Agir Comunicativo e Planejamento Social (uma crítica ao enfoque estratégico). Fiocruz, Rio de Janeiro.

Ross D 1987. Aristóteles. Publ. D. Quixote, Lisboa.

Rossi P 1989. Os Filósofos e as Máquinas. Cia das Letras, São Paulo.

Rowe A 1997. L'Evaluation Axée Sur L'Áutonomie. Bulletin de la Société canadienne d'evaluation: 1-3.

Sala A 1998. O Registro Médico em Serviços Ambulatoriais: a Anotação como Componente da Técnica em Saúde. Tese de Doutorado. Faculdade de Medicina, USP, São Paulo.

Sala A, Nemes MIB, Cohen DD 1996. A avaliação e a prática programática, p. 173-192. In LB Schraiber, MIB Nemes \& RB Mendes-Gonçalves (orgs.) Saúde do Adulto: Programas e Ações na Unidade Básica. Hucitec, São Paulo.

Sala A, Nemes MIB, Cohen DD 1998. Metodologia de avaliação do trabalho na atenção primária à saúde. Cadernos de Saúde Pública 14(4): 741-751.

Schraiber LB 1990. Programação em Saúde Hoje. Hucitec, São Paulo.

Schraiber LB 1993, O Médico e seu Trabalho. Limites da Liberdade. Hucitec, São Paulo.

Schraiber LB 1995. Planejamento e política nas práticas de saúde. Saúde em Debate 47: 28-35.

Schraiber LB 1997. Medicina Tecnológica e Prática Profissional Contemporânea: Novos Dilemas, Outros Desafios. Tese de Livre-Docência. Faculdade de Medicina, USP, São Paulo.

Schraiber LB, Mendes-Gonçalves RB 1996. Necessidades de saúde e atenção primária, p. 20-46. In LB Schraiber, MIB Nemes \& RB Mendes-Gonçalves (orgs.) Saúde do Adulto: Programas e Ações na Unidade Básica. Hucitec, São Paulo.

Schraiber LB, Nemes MIB 1996. Processo de trabalho e avaliação de serviços de saúde. Cadernos FUNDAP 19: 106-121.

Schraiber LB, Nemes MIB, Mendes-Gonçalves RB 1996. Saúde do Adulto: Programas e Ações em Unidade Básica. Hucitec, São Paulo.

Starfield B 1992. Primary Care. Concept, Evaluation, and Policy. Oxford University Press, Oxford.

Teixeira C, Sá MC 1996. Planejamento \& gestão em saúde: situação atual e perspectivas para a pesquisa, o ensino e a cooperação técnica na área. Ciência e Saúde Coletiva 1(1): 82-103.

Testa M 1992. Pensar em Saúde Artes Médicas/Abrasco, Porto Alegre. 